\title{
The BS Theoretical Price of Shanghai 50 ETF Options
}

\author{
Caicai Xu \\ School of Economics, Shanghai University, Shanghai 200444, China \\ xuanzhi19762@163.com
}

Keywords: Black-schools option pricing model; Shanghai 50 ETF options; Closed price; Delta; Rho

\begin{abstract}
The purpose of this paper is to study option pricing problems in the Chinese market based on the Black-Scholes Option Pricing Model, compare the theoretical prices and the actual price and analyze the reason of the difference. It calculated the BS theoretical price of Shanghai 50 ETF call options with different period to lay the foundation for adjusting the module. It selected 60 Shanghai 50 ETF options (forming 11675 sample data),to calculate the BS theoretical price. In the process of calculating the BS theoretical price, it utilized the Wind data and Equivalent substitution to reduce the workload reasonably. Then it use the least square method to analyze the degree of fitting of the BS model. According the result, we find that BS model can explain the actual price of Shanghai 50 ETF option in appropriately. Consequently, investor can estimate the option value on the basis of BS theoretical price in the Shanghai 50 ETF option market.
\end{abstract}

\section{Arrival of Option in China}

Modern options market formed in the 1970s, The oil crisis and shake of fixed exchange rate system triggered a global financial turmoil. In China, After the 1990s the convertible bonds, warrants, foreign exchange options and tools appeared. Then Zhengzhou Commodity Exchange, Shanghai Futures Exchange, and Dalian Commodity Exchange tried to adjust the system and technology. In 2011,the interbank market the yuan against the currency options occurred;3 years later, Sugar options occurred in Zhengzhou Commodity Exchange; and in 2015,Corn options (in Dalian Commodity Exchange ), gold option (in the Shanghai Gold Exchange) and the Shanghai ETF50 options (in Shanghai Stock Exchange), Shenzhen 100 ETF options (in Shenzhen Stock Exchange), China vanke (in Shenzhen Stock Exchange), Bishuiyuan options (in Shenzhen) and the gem ETF options ( in Shenzhen) was launched one after another. Main reason for launching options in our country is to win pricing power, reduce the risk of futures, spot investment opportunity and increase marketing activity. At present, China needs to improve the veriety of option, and cultivate more professional on option. Shanghai 50 ETF options appeared in 2015. Consequently, it's necessary to study the price regularity of Shanghai 50 ETF options through empirical research.

\section{Releted Works}

There are a variety of works about Black-Scholes Option Pricing Model, which classified into two categories: empirical research and theoretical research. In theoretical research, Fischer Black and Myron Scholes argued a groundbreaking research which is called Black-Scholes Option Pricing Model in1970s. However, due to the rigorous assumption, its application was always under restrictions. As a result, many scholar adjusted the model, for instance, Heston (1993) first come up with SV model and Bates (1996) first raised SVJ model. Therefore, they can solve matters pointedly.

In empirical research, the interpret abilities of model are unlike in different cases, other adjustd BS model is not as good as the original BS model sometimes. Mingliang Chen (2006) studied baosteel warrants prices and found a serious shortage of the pricing precision of BS model due to the peak fat-tail distribution warrants, and tried to corrected the model for baosteel warrants. Bin Feng (2008) put forward that SV model and SVJ model have a more high precision than the BS model by empirical study in Hong Kong options market .Dingwei Huang(2009) VG model are more comfortable to describe the currency gains dynamic process than BS model via KS distance test and 
chi-square degree of fit test ,but he also put forward that VG model can't be used to study the martingale pricing problem of option. Yuankun Zhang(2014) demonstrated the effectiveness of BS model by calculating the CSI 300 index options. Xiaobin He(2015) analyzed the European and American options of S\&P 100 index, and discovered that SV model is better than BS model, but the standard deviation of some parameters in SV model is a little biger. In the study of investment fund manager selection, Sydney D. Howell, Axel J. Jägle(2003) found that BS pricing efficiency is very high in the normal range, but the pricing efficiency of BS model is not so good in the start and end time.

As for the adjusted BS model, schoolars usually raised correction schemes by analyzing the character of sample data in order to increase the model validity. Mingliang Chen(2006) uesd EGARCH model to adjust because the sample data didn't satisfy the assumption of the traditional BS model. Yucui Wang(2010) used qualitative analysis and empirical analysis to solve the inconsistent problem between the assumption and the reality. She introduced transaction costs and dividend payments into the traditional BS model and gained a more precise result. Shanghui $\mathrm{Jia}(2010)$ utilize interpolating wavelet collocation method to adjust BS model, and tested the model With European call option, which fully indicated the effectiveness of the method of point collocation. Daniël Linders and Ben Stassen(2016) introduced Gamma model to simulate the Dow Jones index options by Relaxing the assumption in BS model about Geometric Brownian motion.

\section{Empirical Research of BS Model about Shanghai 50 ETF Options}

The Assumption and Formula of BS Model. Initial BS option pricing model was used to prize the option of underlying stocks that have no dividend payments. And there are 6 assumption. (1)The price of underlying stock subjects to Brownian motion. (2)The risk-free interest rate is known and is a constant. (3)There is no dividend payments; (4)Investors can buy any number of the underlying stocks. (5)The options belong to European option. (6)There is no friction in the market. Then the formula is derived by Black and Scholes, which is

$\mathrm{C}=\mathrm{S}_{0} \mathrm{~N}\left(\mathrm{~d}_{1}\right)-\mathrm{Ke}^{-\mathrm{rT}} \mathrm{N}\left(\mathrm{d}_{2}\right)$.

Then introducing dividend payments we acquire the adjusted BS model, which is $\mathrm{C}=\mathrm{S}_{0} \mathrm{e}^{-\mathrm{qT}} \mathrm{N}\left(\mathrm{d}_{1}\right)-\mathrm{Ke}^{-\mathrm{rT}} \mathrm{N}\left(\mathrm{d}_{2}\right)$.

Equivalent Substitution of the BS Model (for Call Option). Based on the BS option pricing model, many stock software introduced Commonly used indicators, such as Delta, Rho, Gamma, etc. Delta and Rho can be described respectively as

$$
\begin{aligned}
& \Delta_{\text {Call }}=\mathrm{e}^{-\mathrm{qT}} \mathrm{N}\left(\mathrm{d}_{1}\right), \\
& \rho_{\text {Call }}=\mathrm{Ke}^{-\mathrm{rT}} \mathrm{N}\left(\mathrm{d}_{2}\right) .
\end{aligned}
$$

Then we can describe BS option pricing formula with Delta and Rho as $\mathrm{c}=\mathrm{S}_{0} \mathrm{e}^{-\mathrm{qT}} \mathrm{N}\left(\mathrm{d}_{1}\right)-\mathrm{Ke}^{-\mathrm{rT}} \mathrm{N}\left(\mathrm{d}_{2}\right)=\mathrm{S}_{0} \Delta_{\text {Call }}-\rho_{\text {Call }} / \mathrm{T}$

Data Filtering and Instructions. (1)Data is from the Wind database, and $r$ is annual risk-free rate of return. (2)According to the existing research, call options and put options are the same in essence, so this paper study the call option only .3)The duration of the Shanghai 50 ETF option range from 0.5 months to 7 months, so this paper select all kinds of option to analyze. (4)The underlying share price is net value of HuaXia Shanghai 50 ETF fund. (5)When it is near to the expiration, the liquidity of option will be very poor, so this paper eliminates the data which is less than four days before the maturity date.

To Calculate the BS Theoretical Price of Sample Data. According to the equivalent replaced BS model, we can get the BS theoretical price of sample data. In order to save the space, this paper demonstrate calculating result about one of Shanghai 50 ETF (code:10000015) in the table 1.

Test of Degree of Fit. After calculating the BS theoretical price of sample data, it use eviews software to test the degree of fit. And we can find the result in Fig. 1, Fig. 2, and Fig. 3. It is obvious that the degree of fit is $\mathrm{R}^{2}=0.9293$, t-statistic $=147, \mathrm{~F}$-statistic $=21609.19$. According the result, BS model can explain the actual price of Shanghai 50 ETF option in appropriately. 
Figure 1. Scatter diagram of BS price and closing price

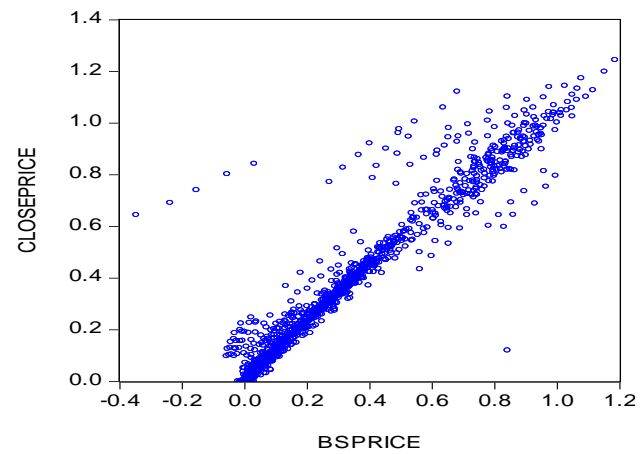

Figure 2. Correlation of BS price and closing price

䕪 Workfile: UNTITLED

(G) Group: UNTTTLED Workfile: UNTITLED:UntitledI

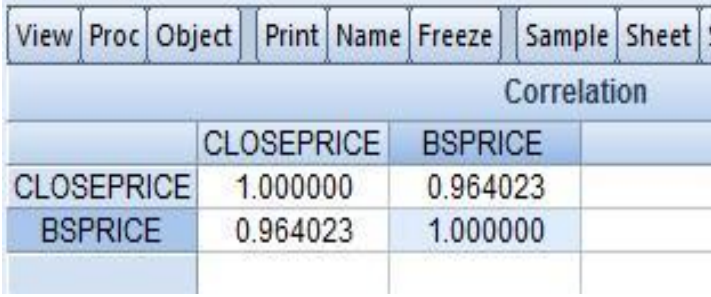

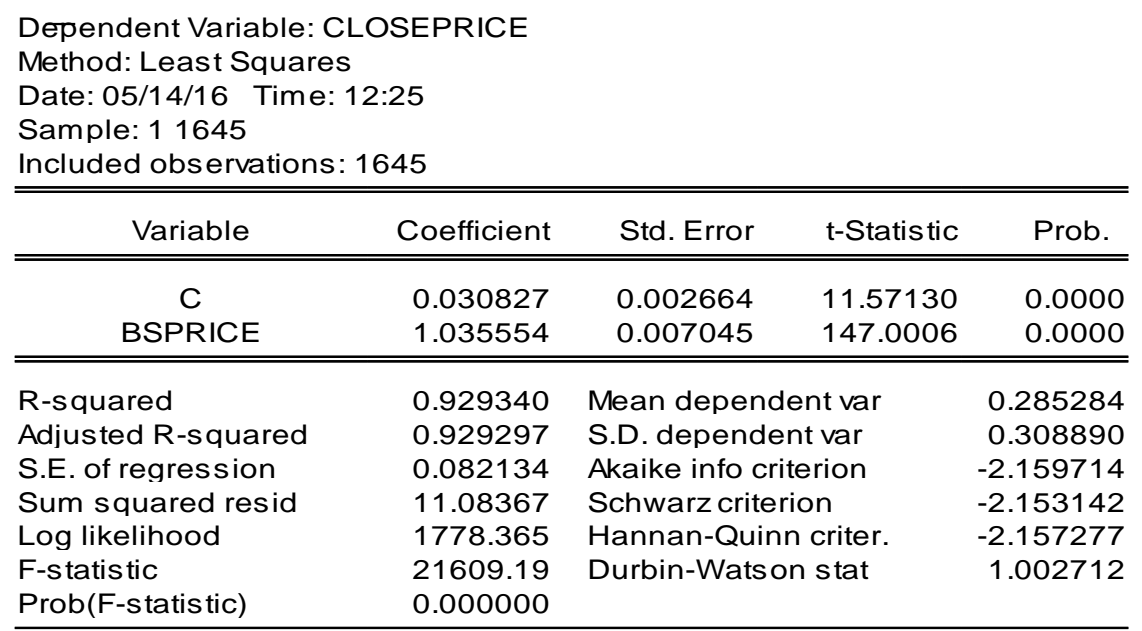

Figure 3. Regression analysis on BS price and closing price.

Table 1. A part of option price based on BS model (data:Wind database)

\begin{tabular}{|l|l|l|l|l|l|l|}
\hline Date & Delta & Rho & $\begin{array}{l}\text { Remaining } \\
\text { holding } \\
\text { period }(\tau)\end{array}$ & $\begin{array}{l}\text { Taking the bottom of } \\
\text { annual remaining } \\
\text { holding period(252/ })\end{array}$ & $\begin{array}{l}\text { HuaXia 50 } \\
\left.\text { ETF( }{ }_{0}\right)\end{array}$ & $\begin{array}{l}\text { BS } \\
\text { theoretical } \\
\text { price(c) }\end{array}$ \\
\hline $2015-2-25$ & 0.4920 & 0.1690 & 39 & 6.4615 & 2.372 & 0.0750 \\
\hline $2015-2-26$ & 0.6330 & 0.2180 & 38 & 6.6316 & 2.443 & 0.1007 \\
\hline $2015-2-27$ & 0.6080 & 0.2040 & 37 & 6.8108 & 2.441 & 0.0947 \\
\hline $2015-3-2$ & 0.6100 & 0.1930 & 36 & 7.0000 & 2.444 & 0.1398 \\
\hline $2015-3-3$ & 0.4830 & 0.1470 & 35 & 7.2000 & 2.363 & 0.0829 \\
\hline $2015-3-4$ & 0.4750 & 0.1420 & 34 & 7.4118 & 2.365 & 0.0709 \\
\hline $2015-3-5$ & 0.4160 & 0.1220 & 33 & 7.6364 & 2.335 & 0.0397 \\
\hline $2015-3-6$ & 0.4240 & 0.1220 & 32 & 7.8750 & 2.339 & 0.0310 \\
\hline $2015-3-9$ & 0.5340 & 0.1460 & 31 & 8.1290 & 2.395 & 0.0921 \\
\hline $2015-3-10$ & 0.0640 & 0.0629 & 30 & 8.4000 & 2.362 & 0.0583 \\
\hline $2015-3-11$ & 0.0646 & 0.0646 & 29 & 8.6897 & 2.375 & 0.0499 \\
\hline $2015-3-12$ & 0.1060 & 0.1036 & 28 & 9.0000 & 2.449 & 0.0717 \\
\hline $2015-3-13$ & 0.1086 & 0.1076 & 27 & 9.3333 & 2.459 & 0.0594 \\
\hline
\end{tabular}




\section{References}

[1] Daniël Linders,Ben Stassen,The multivariate Variance Gamma model: basket option pricing and calibration. Quantitative Finance, 2016, Vol.16 (4), p.555-572.

[2] Bin Feng. The option pricing model based on the Hong Kong market pricing efficiency empirically. Xiamen university. 2008.

[3] Shanghui Jia, Hua Li .Black-Scholes. Option pricing equation of adaptive wavelet algorithm. The practice of mathematics and understanding.2010.

[4] Mingliang Chen, Fixed Black - Sholes warrants pricing theory research assumptions of numerical method. Statistics and decision.2006

[5] Dingwei Huang. Currency options pricing: who VG model with BS model more applicable. Financial development research.2009.

[6] Ying Sun. Black-ScholesOption pricing model of pricing deviation and several fixed pricing model research. Shaanxi normal university.2007

[7] Sydney D. Howell, Axel J. Jägle. Laboratory Evidence on How Managers Intuitively Value Real Growth Options, Journal of Business Finance \& Accounting, 2003, Vol.24 (7-8)

[8] Yucui Wang, Yanna Wang. Black-ScholesCorrection model in the application of the derivative financial instruments. journal of liaoning engineering technology university (social science edition). 2010 .

[9] Qiang Fu, Kai Wang, Xiaoyu Liu. Currency options pricing based on scores, Black - Scholes model and its evaluation test. The price issue. 2008.

[10]SD by Howell. Jagle AJ. Laboratory evidence on how managers intuitively value real growth options. Journal of Business Finance \& Accounting. 2010.

[11]Jens Niemöller, Natalia Rentzsch. Development toward integrated reporting, and its impact on corporate governance: a two-dimensional approach to accounting with reference to the German two-tier system. Journal of Management Control.Vol.25(135-164) 